\title{
Ärztekammer entscheidet erst im Juni
}

Die Delegierten der Ärztekammer haben an der ordentlichen Sitzung vom 29. April 2004 beschlossen, die Wahl des neuen FMH-Präsidenten und die Wahl der Mitglieder des Zentralvorstands auf eine ausserordentliche Sitzung zu verschieben, die am 26. Juni stattfinden soll.

Nach dem überraschenden Schritt von Hans Heinrich Brunner und seiner Ernennung zum Vizedirektor des BAG sah sich die Mehrheit der Delegierten nicht in der Lage, innerhalb so kurzer Frist und mit gutem Gewissen einen neuen Präsidenten zu wählen. Als weiteres wichtiges Argument für die Verschiebung der Wahlen wurde die gegenwärtig laufende Strukturreform erwähnt. Zuerst müsse man das Anforderungsprofil der Kandidaten kennen, bevor man diese wähle, wurde zu bedenken gegeben.

Eine starke Minderheit trat für eine sofortige Wahl ein. Nach Auffassung dieser Delegierten könnte eine Verschiebung der Wahlen als Zeichen der Schwäche der FMH interpretiert werden. Im Kontext der aktuellen Diskussionen zur KVG-Revision müsse sofort ein FMH-Präsident gewählt werden, der gegenüber den politischen Kontrahenten glaubwürdig auftreten könne.

Mit Bestimmtheit hätte letzte Woche ein guter FMH-Präsident gewählt werden können. Alle angetretenen Kandidaten verfügen über das dazu notwendige Format. Mit ebensolcher
Bestimmtheit ist es aber auch als Zeichen politischer Reife zu werten, dass sich die Delegierten nicht unter Druck setzen liessen und möglichen negativen Schlagzeilen über eine Nichtwahl keine Beachtung geschenkt haben. Es hätte von schlechtem politischem Stil gezeugt, in einer solchen unvorbereiteten und teilweise auch unübersichtlichen Situation einen Präsidenten zu wählen.

Die Schweizerische Ärztezeitung SÄZ wird allen FMH-Mitgliedern, die für die Wahl für den Zentralvorstand und für das FMH-Präsidium kandidieren, die Möglichkeit anbieten, sich in einem definierten Umfang in der SÄZ in der Nummer 24, die am 9. Juni erscheint, zu präsentieren. Die Redaktion wird interessierten Kandidatinnen und Kandidaten die entsprechenden Detailinformationen liefern.

Für Beiträge im Zusammenhang mit diesen Wahlen steht die SÄZ bis zum 19. Mai 2004 offen. Propagandistischen Zuschriften möchten wir hingegen nicht Hand bieten. Wir appellieren an alle Mitglieder, den nun eröffneten Wahlkampf in würdigem und sachlichem Stil durchzuführen. Das dringende Gebot der Stunde ist schliesslich, die Glaubwürdigkeit unserer Organisation zu erhalten und zu stärken.

Dr. med. Markus Trutmann Chefredaktor Schweizerische Ärztezeitung 


\section{La Chambre médicale décidera en juin seulement}

Les délégués de la Chambre médicale ont décidé, lors de la séance ordinaire du 29 avril 2004, de reporter l'élection du président de la FMH et celle des membres du Comité central à une séance extraordinaire, qui doit avoir lieu le 26 juin 2004.

Après la décision surprenante de Hans Heinrich Brunner et sa nomination comme vicedirecteur de l'OFAS, la majorité des délégués ne s'est pas vue en mesure d'élire en si peu de temps et en toute bonne conscience un nouveau président. La réforme des structures actuellement en cours a été avancée comme un autre argument important pour reporter les élections à plus tard. Il est essentiel de connaître les profils d'exigences et les qualités des candidats avant de les élire, ont fait valoir certains délégués.

Une forte minorité s'est exprimée en faveur d'un déroulement des élections sans délai. Selon ces délégués, un report pourrait être interprété comme un signe de faiblesse de la part de la FMH. Dans le contexte des discussions actuelles au sujet de la révision de la LAMal, il serait de mise, ont-ils dit, d'élire tout de suite un président de la FMH qui puisse affronter les opposants politiques de manière crédible.
Il est certain qu'un bon candidat aurait pu être élu la semaine dernière. Tous les candidats qui se sont présentés ont le format nécessaire. Il est tout aussi certain que le fait que les délégués ne se soient pas laissés mettre sous pression, et qu'ils n'aient pas craint d'éventuels commentaires critiques de la presse à l'égard d'une nonélection, est un signe de maturité politique.

Le Bulletin des médecins suisses BMS offrira à tous les membres de la FMH qui sont candidats à l'élection au Comité central et à la présidence de la FMH la possibilité de se présenter dans un cadre bien défini dans le numéro 24 , qui paraîtra le 9 juin. La rédaction fournira aux candidats intéressés les informations nécessaires.

Le BMS acceptera des contributions au sujet des élections jusqu'au 19 mai 2004. Par contre, nous n'encourageons pas la publication de textes de propagande. Nous appelons tous les membres de la FMH à mener une campagne électorale digne et raisonnable. Il en va de la crédibilité de notre organisation que nous voulons maintenir, voire renforcer.

Dr Markus Trutmann Rédacteur en chef du BMS 